\title{
ALTERIDADE NOS CURRÍCULOS DE MATEMÁTICA: A INVERSÃO DO VETOR E A AÇÃO DOS ATORES NA ESCOLA
}

\author{
Júlio César Augusto do Valle
} Andréia Lunkes Conrado

\section{INTRODUÇÃO}

No Brasil, país heterogêneo de proporções continentais, é necessário mantermo-nos sempre cuidadosos ao considerar as marcantes diferenças regionais, socioeconômicas e culturais que nos perpassam, a fim de evitar modelos simplificadores da realidade. Tais modelos podem, eventualmente, obscurecer importantes características das multifacetadas problemáticas as quais nos dedicamos como educadores matemáticos preocupados com a incidência da ação política - macro e micro - na/da realidade escolar. Notadamente, no entanto, alguns modelos se mostram úteis às discussões e reflexões em cujos objetos identificamos determinadas similitudes. Há de se enunciar, nesse sentido, que nenhum modelo proposto neste artigo pretende encerrar em si as múltiplas abordagens que nossa temática pode sugerir, mas, ao invés disso, pretende germinar condições necessárias para que o debate essencialmente democrático possa florescer.

Para Paulo Freire (1982, p. 141), a educação "se converte numa oportunidade na qual, ao serem os seus participantes desafiados a superar sua visão ingênua da realidade por outra, crítica e totalizante, vão igualmente clarificando-se ideologicamente”. Assim, do reconhecimento de que os obstáculos à ação político-pedagógica "se encontram na contradição entre a opção revolucionária e o emprego de procedimentos que correspondam à prática da dominação”, depreende-se que o comprometimento freireano com a desmitificação da realidade se dá necessariamente por meio de ações que se desenvolvem a partir da própria realidade - local, contraditória, contingente, porém potencial.

Para isto, é necessário compreender o currículo escolar como um território de representações e identidades contestadas. Ademais, deve-se reconhecer nas prescrições curriculares "a existência de um jogo de correlação de forças que estabelece critérios de validade e legitimidade segundo os quais são produzidas representações, sentidos, e instituídas realidades" (COSTA, 1999, p. 41). Não se deve ignorar, então, que o currículo prescrito é constituído pela disputa de diferentes visões de mundo, às quais poucas ou apenas uma se sobrepõem. 
Dessa maneira, à visão de mundo que predomina nas disputas curriculares é conferido o privilégio de representar a seu modo o conhecimento, a humanidade e, sobretudo, o outro. Posteriormente, tais representações se consolidam e passam a se apresentar como se estivessem justificadas em uma "lógica cristalina". Entretanto, como nos recorda Marisa Costa (1999, p. 60), a "razão" que orienta tais representações tem classe, sexo, etnia, faixa etária e projeto político-filosófico muito bem definidos: "o sujeito da racionalidade ocidental que produziu os conhecimentos identificados como patrimônio cultural da humanidade foi concebido na filosofia ocidental moderna, é unitário, masculino, branco e europeu". Todo o restante são outros. No que se refere ao currículo de matemática, em particular, nota-se a predominância de uma visão única, universal, abstrata e distante da realidade dos estudantes/educandos, que tem produzido injunções matemáticas, interpretadas por Patrick Trabal (2011) como "atos de violência", ao desconsiderar e eliminar práticas, saberes outros modos habituais de conhecimento.

Com efeito, o currículo escolar torna-se responsável pela reprodução dos sentidos de pertencimento ou de exclusão próprios de uma sociedade desigual. Para problematizar e tentar uma via de desconstrução desses sentidos, nos propomos a identificar caminhos potenciais para a construção de políticas curriculares que, atentas às questões brevemente enunciadas, deem espaço e estimulem a alteridade ${ }^{1}$.

\section{CAMINHOS PARA A ALTERIDADE NO CURRÍCULO}

\section{Situação 1:}

Em uma aula de arte, a professora opta por iniciar suas primeiras aulas do ao letivo com o poema "Das pedras", de Cora Coralina. Os alunos copiam o pequeno poema no caderno e começam, aos poucos, a discutir sobre o significado da palavra pedras no poema.

"O que podemos construir com pedras?"

"Casas..." "Muros..." "Calçadas..." "Joias...", dizem os alunos. tempo".

Alguém mais ao fundo: "para formar alicerces, a pedra é dura, resiste ao

Uma voz mais jovem diz "Fulano é uma pedra no meu sapato...".

Todos riem.

A professora lê: "Entre pedras que me esmagavam levantei a pedra rude dos meus versos".

O que a Cora fez com as pedras que a vida lhe deu? E você, o que faria?".

"Revida" diz a jovem... [risos]

\footnotetext{
${ }^{1}$ Alinhamo-nos à concepção de que a alteridade pode ser definida como faz Domite (2014, p. 39): “o primeiro movimento refletido, alteridade um processo que pode levar à re-construção de identidades na diferença - o qual, como dito, procuro pensá-lo no contexto da relação professor-aluno e professor-professor, mesmo reconhecendo-o como um problema da maior abrangência filosófico-político, decorrente dos modos de comunicação, dos modos de ver e de existir distintos".
} 
Uma voz mais baixa, tímida parte de uma das senhoras mais velhas, ao fundo da sala e diz "Quando a gente é mais jovem a gente revida, né? Mas depois a gente aprende que não vale a pena". (CONRADO, 2019, p. 124)

A maneira como se posicionam os atores locais da escola, dentro de uma sala de aula, consiste, sob a perspectiva adotada, em uma fonte potencial e profícua de produção e circulação de saberes que pode, por se apresentar dessa forma, ensinar muito aos pesquisadores do campo do currículo.

Na situação anteriormente descrita, observada em estudo de campo realizado em uma escola num contexto da educação de jovens e adultos, é possível notar a presença de dois modos distintos de compreender "as pedras" apresentadas pelo poema de Cora Coralina, a partir do olhar e das experiências de vidas de duas mulheres, uma mais jovem e outra de mais idade. O diálogo que se estabelece, mediado pela professora, revela o acolhimento às diferenças geracionais presentes na sala de aula e torna visível as diferentes vivências culturais dos estudantes, reconhecendo e tratando o jovem e o velho como sujeitos da alteridade. A atitude da escola, por meio da ação da professora e da voz dos estudantes, sustenta uma política curricular que reconhece os sujeitos da escola como produtores de significados, capazes de questionar e problematizar pontos de vista únicos produzidos por modos hegemônicos de tratar o conhecimento. Essa atitude em direção da alteridade pode ser interpretada como faz Reinaldo Fleuri (2006, p. 513), ao afirmar:

Ou seja, busca-se reconhecer o outro como produtor de significados, no sentido de acolhê-lo e compreendê-lo mediante múltiplas linguagens e estratégias relacionais, deixar-se interpelar por eles, responder-lhe de modo respeitoso e criativo, estabelecer laços de comunicação e de reciprocidade que vivificam as tramas complexas de significados constitutivas dos contextos socioculturais.

A partir desta situação escolar, interessa-nos, pois, reafirmar sobre a importância de desconstruir o lugar subjugado da política curricular reduzida às prescrições oficiais, a fim de resgatar o papel central que deve desempenhar o currículo para a definição das demais políticas educacionais, (formação de professores, avaliação de sistemas, orientações e materiais didáticos), para que se possa avançar em direção a uma política que amplie a relevância da ação dos atores sociais da/na escola (professores, gestores, alunos, funcionários e comunidade escolar) em sua efetivação, dado que estes atores têm sido cada vez mais silenciados por estas políticas.

Tal processo de análise reconhece, de um lado, o papel indutor que desempenham as macropolíticas educacionais e, de outro, procura ressignificá-las a partir da ação dos atores em seus contextos microssociais, ao se voltarem para os dilemas da gestão escolar, da prática docente e das experiências e visões dos sujeitos na aprendizagem matemática, os estudantes. Deste modo, se amplia a análise do processo de construção da política curricular, ao considerar a atuação política dos atores 
por meio de reinvenções, adaptações, resistências ou silenciamentos sobre o que lhes é apresentado como currículo, em suas diversas dimensões.

Podemos afirmar que, pelas teorias tradicionais, os debates em torno dos currículos (numa visão técnica, prescritiva e supostamente neutra) tomavam como objeto a busca de respostas para as perguntas “o que?” e "como?” ensinar. Com as teorias críticas e seu posicionamento sobre o processo de reprodução social e cultural presente nos currículos, o interesse passa a ser "para que?” e "por que?" ensinar, incorporando os conceitos de classe social e poder, e denunciando os mecanismos de manutenção e reprodução das desigualdades na sociedade e na escola. Por fim, as teorias pós-críticas ampliam as bases sociais epistemológicas que sustentam a visão predominante até então acerca do conhecimento e colocam em debate as perguntas “para quem?” e “com quem?” se constrói currículo. Desse modo, as relações de poder deixam de se limitar às questões de classe ou à visão dicotômica dominante-dominado pré-definidas por uma macroestrutura, e passam a analisar o caráter discursivo do currículo denunciando as relações de poder que determinam a legitimidade do que deve ser considerado como conhecimento a ser disponibilizado para a escola, abrindo espaço para novos discursos e saberes.

Defende-se assim uma concepção de currículo apoiada em novas bases epistemológicas, capazes de articular as noções de conhecimento, identidade e poder, privilegiando o tratamento da diversidade e das diferenças culturais como centrais nos processos de desenvolvimento curricular, de forma a reconhecer o modo como se constrói e se produz conhecimento, dentro e fora da escola, de forma mais plural do que fora tratado até então, em especial no que se refere ao currículo de matemática.

Neste sentido, com o compromisso de uma prática fundamentada pela alteridade para acolher o tratamento da diversidade de povos e das diferenças socioculturais nos múltiplos contextos de produção curricular, adotamos princípios da análise sociológica sustentada por uma corrente da sociologia francesa, denominada Sociologia Pragmática (BOLTANSKI e THÉVENOT, 1991) que procura estabelecer relações entre os contextos macro e micropolíticos. Tal perspectiva teóricametodológica nos permite avançar em termos das disputas políticas e epistemológicas acerca do conhecimento, em seus variados territórios de produção.

A Sociologia Pragmática, Sociologia das Provas, ou ainda, Nova sociologia, pode ser compreendida como um movimento sociológico nascido na França em torno dos anos 1980, que emerge de uma mudança paradigmática marcada pelo deslocamento da busca por determinantes estruturais como condicionantes da ação dos atores, para uma análise da própria ação dos atores, e 
dos fatores que a eles importam, para só então indicar elementos estruturantes desta ação. Como bem sintetizou Corrêa,

A ideia é simples: na impossibilidade de se manter um ponto de vista absoluto, uma metafísica externa aos atores que seja capaz de fundar, para além dos próprios, um princípio de explicação último de seus comportamentos, de suas ações, Latour propõe uma reorientação de perspectiva com relação à sociologia clássica. 0 principal objetivo do autor é oferecer uma alternativa capaz de escapar do social substantivo, quer dizer, do social como quadro de referência absoluto e explicativo das coisas (a sociedade como "Deus", em Durkheim, ou "estrutura estruturada", em Bourdieu) para caminhar na direção de uma sociologia sensível às variações e critérios ou princípios de avaliação mobilizados e tornados visíveis, pelos atores, em situações problemáticas ou em controvérsias. (CORRÊA, 2014, p. 41)

Para Diogo Corrêa, a transição para a nova sociologia francesa, em relação aos autores chamados neoclássicos ${ }^{2}$, se deu pela passagem "do problema do social para o tratamento do social como problema" ou "da escala da sociologia para a escala dos atores". Neste processo, o social deixa de ser fator explicativo do mundo social e torna-se aquilo que deve ser explicitado e explicado por meio do modo como os atores fazem, desfazem e refazem suas associações heterogêneas (CORRÊA, 2014, p. 39).

Deste modo, a crise dos grandes paradigmas que impulsionou a virada pragmática no desenvolvimento das ciências sociais no contexto francês, marca o fim das explicações totalizantes e amplia as categorias explicativas tradicionais de classe, estrutura, sociedade, movimentos sociais, agora aliadas a uma abordagem que privilegia indivíduos compreendidos como atores e suas experiências. Neste sentido, a visão de totalidade e de regularidade presente na sociologia clássica é confrontada pelas microssituações, pelos momentos de ruptura e pelas controvérsias (DIAS \& CORRÊA, 2016, p. 69).

A visão que se desenvolveu pela sociologia clássica, interpreta a ação dos indivíduos pautada por uma matriz de estrutura macrossocial pré-estabelecida, definida por práticas mediadas pelo habitus, no sentido de Bourdieu. Desse modo, ao analisar o contexto escolar, assumem um habitus escolar institucionalizado, pautado por mecanismos de controle e ação do Estado, que opera como balizador da ação dos sujeitos. Já numa visão pragmática, os limites e reenquadramentos da ação dos sujeitos podem estar pautados por outras estruturas exteriores produzindo resistências e formas alternativas de ação que, ao serem assumidas pelo pesquisador, promovem "mergulhos em territórios empíricos diversificados" e "fazem prova das fragilidades que aquela lente produz no modo de

\footnotetext{
${ }^{2}$ Pierre Bourdieu, Harold Garfinkel, Norbert Elias, Anthony Giddens, Ervin Goffman, por exemplo.
} 
interpretar questões trazidas pelos objetos que está a investigar amiúde" (RESENDE \& DIONÍSIO, 2016, p. 202).

Assumimos assim uma inversão do vetor curricular, no sentido descrito por Valle e Santos (2018) ao considerar que partir das realidades locais das escolas, não significa apenas (re)elaborar práticas, mas também subsídios teóricos de reflexão sobre as práticas e, consequentemente para as políticas que as subsidiam, produzindo e demandando novas políticas, rompendo a ordem então estabelecida que parte da prescrição para a realidade da escola. Para os autores esta inversão tem como princípio "a ruptura com a prática prescritiva, neo-tecnicista, caracterizada pela separação entre o pensar e o fazer currículo" (VALLE \& SANTOS, 2018, p. 1217).

Os autores elucidam que inverter o vetor significa a problematização e a recusa de "políticas curriculares construídas sob a égide desse paradigma se dão numa direção, isto é, partem dos gabinetes, das secretarias e, em última instância, do Ministério, rumo às escolas" (p. 1218). Inverter o vetor da política curricular significa identificar, construir e privilegiar mecanismos que estimulem as escolas à desinvisibilização de seus currículos pensadospraticados.

Elucidamos que a inversão do vetor do currículo praticada como política curricular, por exemplo, durante a gestão de Paulo Freire na Secretaria Municipal de Educação de São Paulo, de 1989 a 1992, traduziu-se no protagonismo docente em parceria permanente com a comunidade, o território em que a escola se inseria e a contribuição crítica de especialistas, no movimento de reorientação curricular:

Era esperado que o caminho do ensinar e do aprender fosse mais ou menos por etapas como: partir de um tema eleito pela comunidade escolar e/ou grupo em sala de aula - por isso, em geral, fora do terreno de uma disciplina propriamente escolar -, problematizar tal tema junto aos alunos, levando-os a formular questões e, a partir das questões formuladas, desenvolver os conhecimentos ditos escolares. (FORNER \& DOMITE, 2014, p. 160)

Segundo Antonio Flávio Moreira (2000, p. 114), “os currículos pautados nos princípios de Freire deveriam ter como eixo organizador as necessidades e as exigências da vida social, não as disciplinas tradicionais". Essa maneira de conceber o currículo origina-se fundamentalmente de uma perspectiva segundo a qual "o currículo não é, pois, constituído de fatos, nem mesmo de conceitos teóricos e abstratos", mas, ao invés disso, “o currículo é um local no qual docentes e aprendizes têm a oportunidade de examinar aqueles significados da vida cotidiana que se acostumaram a ver como dados e naturais" (SILVA, 2011, p. 40). Em suma, "o currículo é visto como experiência e como local de interrogação e questionamento da experiência". 
Deste modo, a escola e seus atores constituem a própria arena das disputas, dos conflitos e dos acordos curriculares. Assim, a análise das "situações de prova" (CORRÊA, 2014, p.44) vividas neste contexto microssociológico produz subsídios práticos e teóricos capazes de fomentar novas demandas e novas soluções para as macropolíticas. No sentido da Sociologia Pragmática, as situações de prova indicam inovações e rupturas que introduzem um novo objeto no ambiente, para o qual os sujeitos não estão preparados, produzindo um deslocamento no tempo e no espaço por meio de novos dispositivos que já não mais correspondem nem a sua cultura nem aos seus hábitos anteriores.

\section{OS PRATICANTESPENSANTES ${ }^{3}$ DO CURRÍCULO E O TEMPO DOS ATORES NA ESCOLA}

Ao propor uma construção curricular com garantia da presença do outro, suas vozes, suas histórias e seus saberes, pelo acolhimento das diversidades e das diferenças, entendemos ser urgente um caminho em direção da alteridade nas políticas curriculares em geral, e no currículo de matemática.

Em síntese, propomos atestar a convergência de um currículo inspirado por rupturas, controvérsias e problemáticas cotidianas - sustentado pela diretriz sociológica que privilegia a ação dos atores sociais - e, neste sentido, orientados pela inversão do vetor tradicionalmente adotado na produção e "implementação" das políticas curriculares, propomos um caminho que descarte a prescrição curricular como método e esteja permeável ao tempo dos atores, em seus variados espaços locais.

De modo a evidenciar tais disputas, apresentamos outras duas situações observadas em estudo de campo desenvolvido por Andréia Lunkes Conrado (2019) em um Centro Integrado de Educação de Jovens e Adultos, Cieja, no município de São Paulo, com oferta de ensino presencial, em horários e modelos alternativos, a fim de acolher a necessidade da população adulta de conciliar as demandas de estudo com outras necessidades da vida, como as exigências do trabalho e da família.

A articulação da carga horária diária com o currículo da escola, entre o Ensino Fundamental I e II, se desenvolve com duração total de quatro anos, organizados em quatro módulos e a ampla diversidade de alunos e alunas determina as ações pedagógicas da escola, como informado no blog da instituição ${ }^{4}$ :

\footnotetext{
${ }^{3}$ Valemo-nos, aqui, como em outros momentos deste texto, de uma possibilidade enunciativa bastante utilizada por pesquisadoras do campo do currículo que se mobiliza na superação de certas dicotomias na própria maneira de enunciálas. (OLIVEIRA \& SGARBI, 2008)

${ }^{4}$ O blog pode ser acessado por meio do seguinte link: http://ciejacambuci.blogspot.com/
} 
A característica mais marcante do CIEJA é a diversidade: alunos migrantes de várias partes do Brasil (principalmente da região Nordeste) e de outros países, com idades, necessidades, credos, cores, orientações, buscas e sonhos diferentes. Ao longo de toda esta trajetória, muitos educadores e funcionários deram sua contribuição para que mais de três mil alunos tenham concluído o Ensino Fundamental e que muitos outros, egressos de nossa escola, tenham se formado no Ensino Superior. Por tudo isso e muito mais, o CIEJA continua enfrentando os desafios, promovendo a construção do conhecimento para a vida social, política e profissional indispensáveis ao exercício ativo e crítico da cidadania.

Além disso, a escola participa do Programa Transcidadania, da Prefeitura de São Paulo, “destinado ao acolhimento da população LGBTT, em especial, travestis e transexuais, em situação de vulnerabilidade, oferecendo oportunidade de estudo e formação profissional às participantes do programa, que recebem uma bolsa de estudos para frequentar as aulas” (SÃO PAULO, 2019, s.p.). A chegada do Transcidadania ao Cieja trouxe uma série de desafios à gestão da escola, que recebeu 85 alunos e alunas, o maior número entre os Ciejas, em função de sua proposta pedagógica e de sua localização, mais próxima da região central da cidade.

A escola, que se apresenta como "uma escola para todos", acolhe também, deficientes, idosos, jovens em liberdade assistida, abrigados, refugiados, mulheres e homens de várias idades, sendo reconhecida como um espaço acolhedor que assume as diferenças entre os alunos como parte de seu projeto político pedagógico. É possível perceber que todos se sentem acolhidos em suas necessidades e particularidades, muitos com relatos de exclusão, discriminação e violência, vividos em suas trajetórias de vida e escolar. Em um contexto multicultural como o mencionado, questões de classe, gênero, raça, etnia, geração, entrelaçam-se à vida social e se revelam no interior das salas de aula e no espaço escolar, exigindo acolhimento de cada professor no trabalho com as disciplinas escolares. Nesse sentido, as situações descritas a seguir sugerem exemplos deste repertório que o aluno traz para o ambiente escolar e que podem potencializar novos processos de produção curricular, abertos a ressignificações. Tais situações podem nascer de conflitos ou acordos, quando acolhidos pela escola e pelo professor, numa postura de escuta e valorização de um outro modo de fazer e saber, em direção à alteridade.

\section{Situação 2:}

Em uma aula de matemática, na tentativa de sair de um modelo mais tradicional de ensino, envolvendo operações básicas, pautado no cálculo escrito, exato e formalizado no quadro, o professor e a pesquisadora propõem uma atividade evolvendo estratégias de cálculo mental. Optam por começar com uma atividade que denominaram "é bom saber de cabeça", como dobros, triplos, metades, quíntuplos, somas e multiplicações de inteiros e pares de números que somam 10, para "facilitar as contas". Os alunos se envolvem com a ideia e, de fato, pareciam se sentir auxiliados por aquela forma de calcular. Aos poucos a atividade passa a explorar estratégias de cálculo mental envolvendo situações mais abstratas do tipo "Tiro 450 
de 900, quanto tenho?" ou "Quanto é 4 vezes 253?"; e outras mais concretas como em "Será que com R $\$ 1.500$ eu consigo comprar um TV de R\$ 686 e uma geladeira de R \$ 532?”. Os alunos vão apresentando outras estratégias, diferentes do cálculo escrito por algoritmos, e vão aparecendo outros modos de calcular. (...) Uma das alunas mais jovens, com pouco mais de 20 anos, vai revelando inúmeras habilidades e rapidez em fazer os cálculos mentalmente, o que também vai sendo compartilhado com a sala, a partir de perguntas do tipo: "Como você pensou?". Em um diálogo, a pesquisadora pergunta: "Com quem você aprendeu a calcular assim?" e a aluna responde "Aprendi com meu pai. Meu pai tinha uma lojinha e eu ajudava ele vendendo algumas coisas, ele me ensinou a fazer assim". Já por outro caminho, uma das alunas mais velhas, sempre muito dedicada e sentada na primeira fileira, embora compreendesse bem o cálculo por meio do uso de algoritmos, mesmo para fazer contas de cabeça, passou a ficar muito confusa sobre o que era isso que estávamos propondo. Diante de suas dúvidas, em certo momento da aula, depois de o professor e a pesquisadora apresentarem diversas estratégias possíveis, pergunta: "No ENEM, tem que fazer assim?". (CONRADO, 2019, p. 126)

\section{Situação 3:}

Em uma entrevista entre a pesquisadora e um aluno de origem haitiana, o diálogo segue:

Pesquisadora - Como é que você vê as aulas aqui? Que interesses e que dificuldades você encontra aqui na matemática?

Quenel - Na verdade tem uma coisa... que... eu não sabia falar em português. E na hora de algum professor tá falando, tem que ter paciência, que sabe que o outro é estrangeiro. Por exemplo, é por isso mesmo que eu falei, no Cieja, pelo que eu vi, os professores e os alunos tudo ajuda eu, entendeu?...Se eu não sei uma coisa... Matemática foi ótimo para mim. O professor está muito bem. Se ele está fazendo alguma coisa que eu já sei, por exemplo do Haiti, ele falou "esse aqui que você tá fazendo é boa eu quero aprender também", entendeu?

Pesquisadora - Ele quer aprender com o seu jeito?

Quenel - Com o meu jeito. Eu também queria aprender com ele o que ele fizer bem melhor, por enquanto. Às vezes eu passei longe... mas pra ele, ... pra ele que tá mostrando para a gente é mais fácil.

Pesquisadora - E ele valoriza o que você faz?

Quenel - Ele valoriza o que eu sei. (CONRADO, 2019, p. 140)

As duas narrativas traduzem situações problemáticas, controvérsias e acordos construídos pelos atores, alunos, alunas, pesquisadora e professor de matemática e revelam modos de interpretar, de calcular, de fazer matemática, que colocam em diálogo, ou confronto, expectativas curriculares em relação aos conteúdos escolares, previstos no currículo oficial, com outras formas de saber, fazer e agir dos atores, em uma situação de escuta, acolhimento e alteridade. Revelam assim, distintas visões, desejos e preocupações em relação aos conhecimentos matemáticos propostos pela escola, pautados por referenciais próprios, interesses e histórias de vida, influenciados pelas idades, pelos gêneros, pelas origens e pelas expectativas de futuro dos sujeitos.

Ao abrir espaço na sala de aula para aquilo que se mostra diferente e diverso, é possível tornar visível as polissemias, a variedade de discursos formas de interpretação sobre conceitos até então 
considerados homogêneos e únicos, dando lugar a uma produção coletiva de significações partindo das diferentes atribuições de sentido construídas pelos alunos e alunas.

Na Situação 2, destaca-se a atribuição (ou não) de valor aos saberes construídos pelas duas alunas: a da aluna jovem que revela um modo incomum e particular de cálculo aprendido no contexto familiar por meio de um parente mais velho; a da aluna mais velha que apoia o seu modelo mental de cálculo numa estrutura bastante formal e rígida construída por meio de sua pouca vivência escolar na infância. Nota-se a partir da vivência em campo que, enquanto a aluna mais jovem parece atribuir valor positivo ao seu modo distinto, próprio, de cálculo, herdado e aprendido do pai, fora do contexto da escola e por ela incorporado pelo uso e efetividade na resolução de situações cotidianas (escolares e não escolares); a aluna mais velha parece colocar em suspeição a validade de seus próprios modos de calcular, por ela utilizados por toda a vida em situações não escolares, para então adaptar-se ao modelo vigente, aquele considerado como válida pelo sistema de avaliação, no caso, o ENEM.

Com efeito, existem investigações que se dedicam a demonstrar que a matemática e seu ensino têm sido centrais para a articulação de discursos meritocráticos, organizando seu conteúdo para um propósito ideológico, associado à "racionalidade, neutralidade, igualdade de condições e autoridade para dizer o que é verdadeiro ou falso, incontestavelmente" (SILVA, 2013, p. 50). Esse mesmo autor, Alexandre Silva, afirma, inclusive, que "temos a matemática eleita como a instância transcendental que, ao ocupar o tribunal supremo da razão, vai ter legitimidade para pronunciar quem tem ou não mérito".

Lamentando que o conhecimento matemático seja protagonista da tragédia ocasionada pelo discurso meritocrático em nossa sociedade, Silva elucida que "a legitimidade operacional dos jogos matemáticos de linguagem para se contemplar propósitos sociais inequívocos é ideologicamente usada e transfigurada para se legitimar a inequivocidade do próprio discurso meritocrático" (SILVA, 2013, p. 204). Sob essa perspectiva, o discurso meritocrático articulado ao conhecimento matemático traz implicações significativas para "a constituição de um currículo escolar que prioriza o conhecimento científico, mais precisamente o matemático, em relação às artes e às humanidades” ( $p$. 205) - valendo-se da e contribuindo para a "docilização" da matemática, distanciando-a de leituras mais críticas da sociedade.

A contribuição de Silva se dá, portanto, no sentido de, elucidando como conhecimento matemático e discurso meritocrático estão implicados na escola moderna, auxiliar-nos no entendimento de que "a composição do currículo oficial na conjuntura das políticas educacionais 
liberais insere-o no sentido da sua grande utilidade nos processos meritocráticos escolares" (SILVA, 2013, p. 198).

Em síntese, podemos afirmar que embora a proposta da pesquisadora e do professor inserindo novos modos de cálculo esperava dar visibilidade, acolher e valorizar as diferenças de cálculo entre os alunos, a pergunta final da aluna sobre o ENEM define os conflitos e controvérsias em torno das disputas em relação ao currículo imposto por meio de uma avaliação externa, seletiva e excludente capaz de definir o que deve ser considerado como conhecimento válido em contraposição aos saberes práticos construídos a partir das situações de vida e das histórias dos sujeitos.

Na Situação 3, é possível observar um deslocamento em relação a esses critérios de validação dos conhecimentos ao revelar o modo como o aluno, estrangeiro, em situação de refúgio no Brasil, consegue perceber o seu modo de falar, de ser e de calcular, ao mesmo tempo em que incorpora o modo de fazer do professor, produzindo a alteridade que permite a troca de significações para os conteúdos e conhecimentos, dando a ele poder para definir seus próprios critérios de validade.

As duas situações indicam gestos, inspirados epistemológica e metodologicamente, do professor e da pesquisadora, que desenvolvem uma forma de problematizar o lugar privilegiado do cálculo escrito, formal, exato, por algoritmos e respostas únicas, para dar lugar ao cálculo estimado, aproximado, mental e voltado para a resolução de situações mais concretas do cotidiano dos alunos. Tais exemplos podem indicar inversões curriculares para o que nomeamos caminhos para a alteridade na sala de aula de matemática, numa busca por fazer emergir a diversidade comumente silenciada neste contexto.

\section{CONSIDERAÇÕES PRELIMINARES}

Como procuramos demonstrar por meio das três situações descritas - a polissemia das pedras, revelando suas possíveis ressignificações; os procedimentos de cálculos mentais, filtrados por uma aluna com o critério de uso no ENEM e as formas de se fazer matemática, quando respeitadas pelo professor -, existem modos de direção, conforme enuncia Domite (2014), explicitáveis sobre como o currículo de matemática pode se construir a partir da potencialidade dos cotidianos escolares, permeados por conflitos e acordos entre seus atores, praticantes do currículo, em favor da alteridade como princípio. Nesse sentido, sublinhamos a convergência da sociologia pragmática com os estudos do cotidiano, ao passo em que ambas privilegiam "a importância sociológica da vida cotidiana, das possibilidades efetivas de ação dos diferentes sujeitos sociais em diferentes circunstâncias e à 
impossibilidade de contemplarmos a sua complexidade característica por meio de estudos estruturais" (OLIVEIRA \& SGARBI, 2008, p. 68)

A partir dos estudos de Silvio Gallo (2008), consideramos a alteridade como a possibilidade de percepção do outro e, desse modo é possível pensar o outro de modo diverso, o que implica na aceitação do mundo como múltiplo, e não como único. Ao assumir a educação como resultado de uma produção social, cultural e epistemológica que se constrói no coletivo, no encontro e no reconhecimento do outro, aceitamos o papel por ela desempenhado na gestão das diferenças e das alteridades. Nesse contexto, Gallo (2008, p. 11) destaca a necessidade da política e da democracia se construírem como uma "política do outro", ou como uma "política da diferença", que pede tolerância, produção de consenso, diálogo e escuta. Desse propósito, afirma o autor a necessidade de tomar o outro como outro, no sentido de uma política da diferença "que pensa o coletivo como conjunto de diferenças".

Sob essa perspectiva, transpor a referência organizadora do trabalho pedagógico da centralidade dos conteúdos à leitura, interpretação e intervenção da/na realidade constitui parte importante das características da inversão do vetor em debate, privilegiando a alteridade como princípio. Outro fator relevante desse movimento consiste no papel desempenhado às disciplinas escolares, como lentes capazes de permitir compreensões distintas e multifacetadas de um mesmo fenômeno. Afinal, uma tensão bastante habitual nas políticas de currículo emerge precisamente do trabalho com as disciplinas - dado que existe um pressuposto na literatura do campo de que a constituição histórica dos saberes disciplinares e a organização estrutural da formação de professores constituiriam impeditivos intransponíveis a todo movimento de reorganização crítica do currículo. Espera-se que o saber da escola permita tanto a compreensão de sua realidade, como também - e em maior medida, sob a perspectiva que defendemos - confira o poder de alterar a realidade com base na interpretação que fazem dela.

Fazerpensar o currículo dessa maneira traz implicações significativas para a organização do ensino de matemática. Nele, a ênfase passa a estar tanto sobre o diálogo como sobre o pensar junto com o outro, emergentes na obra de Domite: "acho que podemos afirmar que eram dois os grandes objetivos de Paulo Freire no âmbito da educação: construir um espaço para o oprimido fazer suas denúncias e fazer compreender a educação como uma atitude política e não técnica" (DOMITE \& FORNER, 2014, p. 169). Articulando os princípios de Freire aos propósitos da educação matemática, diferentes autores concluiriam, como Ole Skovsmose e Paola Valero (2005, p. 66) que levar em conta o que os alunos trazem - enquanto seus foregrounds, nas palavras dos autores - como repertório social e experimental do que conhecem sobre sua realidade, pode ser um caminho profícuo para 
discutir como os processos de inclusão e exclusão são determinantes para os processos de aprendizado dos alunos.

Sob essa perspectiva, os autores afirmam que "com boas razões, pode ser argumentado que uma estratégia de baixo para cima possibilita para estudantes e professores serem incluídos nas tomadas de decisão curricular, o que é essencial para que a educação faça parte de processos democráticos na sociedade" (SKOVSMOSE \& VALERO, 2005, p. 68). Afinal, como já lemos em ambos os autores, não há uma relação intrínseca da educação matemática com o fortalecimento de uma formação cidadã, crítica ou democrática.

Reconfigura-se, assim, o papel do ensino de matemática diante da necessidade de conceber a sala de aula como espaço privilegiado da ação social - onde se educa para a práxis, segundo Freire (1982). Desconhecemos, por isso, caminhos para conceber os alunos como sujeitos políticos - ao invés de somente cognitivos - no âmbito das políticas curriculares prescritivas do conhecimento oficial, dado que, nelas, os alunos têm sua possibilidade de ação social estreitada de maneira, inclusive, violenta, como veremos. As políticas curriculares, inspiradas em Freire e na inversão do vetor curricular, de outro lado, se apresentam tendo como pressuposto o fato de que alunos e professores são sujeitos políticos que, distanciando-se da tradicional recusa dessa dimensão, têm também o currículo como espaço de ação social.

Quando tratamos das possibilidades de se inverter o vetor das políticas curriculares, deve ficar evidente, portanto, que são diferentes não como possibilidades de currículos, mas, ao invés disso, como práticas políticas contrárias, especialmente em função da manutenção das desigualdades sociais e recrudescimento das políticas democráticas. Não faz sentido, quando privilegiamos os cotidianos e a ação dos atores na escola, falar de "implementação curricular". Afinal, inverter o vetor do currículo significa inverter a lógica que orienta a constituição de tais políticas e também suas finalidades.

Torna-se mais e mais urgente, por isso, encontrar tais alternativas como saídas possíveis capazes de superar os danos causados por práticas prescritivas que ignoram ingênua ou maliciosamente a potência dos cotidianos escolares. É preciso, enfim, identificar metodologias e epistemologias apropriadas para confrontar e problematizar as políticas curriculares postas em prática atualmente no país, devido à incapacidade de acolher esses cotidianos. Metodologias e epistemologias que, como aquelas mobilizadas por Freire, inverteram um vetor naturalizado de produção, circulação e implementação em favor de outro, que habilita localmente os atores envolvidos e consideram suas vozes, experiências e interesses para a construção de um projeto educacional viável. 
A sociologia pragmática, valendo-se dos conflitos, dos acordos e de outras situações significativas experimentados no cotidiano escolar para estruturar reflexões que realmente sejam capazes de acolher essas narrativas, essas presenças, mostra-se, cada vez mais, como um desses caminhos profícuos. Nesse sentido, inverter o vetor do currículo, privilegiando a ação dos atores locais, pode garantir não somente a manutenção, mas também a radicalização do sentido público da escola pública, desde o pressuposto básico de acolhimento da diferença - de todos - até o afastamento de práticas excludentes, seletivas, e discriminatórias que, oriundas do modelo de mercado aplicado à educação, corrompem esse sentido público, contaminando-o com critérios de validação provenientes das estruturas de poder - como vemos no caso em que o ENEM foi mencionado em uma das situações.

A retomada do sentido público da educação, em sua radicalidade, nos inclina ao entendimento de que o currículo não pode ser pré-determinado, pois qualquer forma de concebê-lo previamente isolaria aspectos fundamentais de suas políticas que somente se desvelam nos cotidianos escolares, como tensões, limites, possibilidades e potenciais próprios de cada comunidade.

Fortalecer o sentido público das escolas públicas se faz necessário para que possam se resguardar dos assédios do mercado e de seus interesses, valendo-se, para isso, das demandas sociais mais emergentes em cada comunidade e em cada indivíduo como disparadoras do ato educativo - o que depende, não há dúvida, do poder que lhes será entregue, tanto política, como pedagógica e financeiramente para sua efetivação no currículo, afastando interesses privados da lógica de constituição do trabalho pedagógico. "Optamos pela vida" - para usar uma expressão de Giroux (1997, p. 156) ao optarmos por uma escola viva, interessada por e imersa nos cotidianos de sua comunidade.

\section{REFERÊNCIAS}

BOLTANSKI, L.; THÉVENOT, L. De la justification: les économies de la grandeur. Paris: Gallimard, 1991.

CONRADO, A. L. O lugar da diversidade no currículo de matemática: relações entre macropolíticas e a ação dos atores locais. 2019. 190f. Tese de Doutorado - Faculdade de Educação, Universidade de São Paulo, São Paulo, 2019.

CORRÊA, D. S. Do problema do social ao social como problema: elementos para uma leitura da sociologia pragmática francesa. Política \& Trabalho: Revista de Ciências Sociais, 40, pp. 35-62, 2014.

CORRÊA, D. S.; DIAS, R. C. Crítica e os momentos críticos: de la justification e a guinada pragmática na sociologia francesa. Mana, 22, 1, pp. 67-69, 2016.

COSTA, M. V. Currículo e política cultural. In: COSTA, Marisa. Vorraber. (org.) O currículo nos limiares do contemporâneo. Rio de Janeiro: DP\&A, 1999, pp. 37-68.

DOMITE, M. C. S. Na trilha da etnomatemática: alteridade e escuta em Freire. Em: ENCONTRO DE ETNOMATEMÁTICA DO RIO DE JANEIRO, 1, pp. 37-50. Rio de Janeiro: Anais do EEtnomat-RJ, 2014. 
FLEURI, R. M. Políticas da diferença: para além dos estereótipos na prática educacional. Educação e Socidedade, 27, 95, pp. 495-520, 2006.

FORNER, R.; DOMITE, M. C. S. Um encontro entre Paulo Freire e a educação matemática. Revista Internacional de Educación para la Justicia Social (RIEJS), 3, 1, pp. 157-172, 2014.

FREIRE, P. Ação cultural para a liberdade. Rio de Janeiro: Paz e Terra, 1982.

GALLO, S. Eu, o outro e tantos outros: educação, alteridade e filosofia da diferença. IN: CONGRESSO INTERNACIONAL COTIDIANO: DIÁLOGOS SOBRE DIÁLOGOS, II, 2008, Niterói. Anais. Niterói: Editora da UFF, 2008.

GIROUX, H. Pedagogia radical: subsídios. São Paulo: Cortez, 1983.

MOREIRA, A. F. B. Propostas curriculares alternativas: limites e avanços. Revista Educação \& Sociedade, 21, 73, pp. 109-138, 2000.

OLIVEIRA, I. B.; SGARBI, P. Estudos do cotidiano e educação. Belo Horizonte: Autêntica Editora, 2008.

RESENDE, J. M. V. S.; DIONÍSIO, B. Itinerários à luz da Sociologia Pragmática: o que os lugares comuns trazem à comunalidade escolar. Terceiro Milênio: Revista Crítica de Sociologia Política, 6, 1, pp. 198-235, 2016.

SÃO PAULO/ Secretaria de Desenvolvimento Econômico e Trabalho. Projeto Reinserção Social Transcidadania. Disponível

em:

<https://www.prefeitura.sp.gov.br/cidade/secretarias/desenvolvimento/cursos/operacao_trabalho/index.php?p=170430>

. Acesso em: 28 jun. 2019.

SILVA, A. Meritocracia, educação e matemática: um estudo relacional. 2013. 156f. Tese de Doutorado - Faculdade da Educação, Universidade Estadual de Campinas, Campinas, 2013.

SILVA, T. T. Documentos de identidade: uma introdução às teorias do currículo. Belo SILVA, T. T. Documentos de identidade: uma introdução às teorias do currículo. Belo Horizonte: Autêntica, 2011.

SKOVSMOSE, O.; VALERO, P. Mathematics education and social justice. Utbildning \& Demokrati, 14, 2, pp. 57-61, 2005.

TRABAL, P. Uma sociologia de la ensenanza de las matemáticas. Traducción del francês por Alejandro Rendón Valencia. Revista Educación y Pedagogia, 3, 59, pp. 227-240, 2011.

VALLE, J. C. A.; SANTOS, V. M. Interver o vetor do currículo: o Movimento de Reorientação Curricular de Freire em debate. Revista e-Curriculum, 16, 4, pp. 1207-1233, 2018. 


\title{
ALTERIDADE NOS CURRÍCULOS DE MATEMÁTICA: A INVERSÃo DO VETOR E A AÇÃO DOS ATORES NA ESCOLA
}

Resumo: Neste texto, nosso propósito consiste em descrever as convergências de pesquisas sobre políticas curriculares que vêm enfatizando a necessidade de que a macropolítica tenha como princípio estruturante certo grau de permeabilidade em relação à ação e ao tempo dos atores das/nas escolas, em seus variados contextos. Para isso, defendemos um caminho para a alteridade nas políticas curriculares, em especial de matemática, que substitua a prescrição curricular como paradigma e oriente-se por uma inversão do vetor curricular, que produza um movimento capaz de acolher a diversidade cultural e as diferenças representadas por situações de rupturas, controvérsias e problemáticas cotidianas que marcam o território escolar.

Palavras-chave: Currículo. Sociologia Pragmática. Diferenças.

\section{OTHERNESS IN MATH CURRICULUM: THE INVERSION OF THE VECTOR AND THE ACTION OF ACTORS AT THE SCHOOL}

\begin{abstract}
In this text, our purpose is to describe the convergence of research on curriculum policies that have emphasized the need for macropolitics to have as a structuring principle a certain degree of permeability in relation to the action and time of local actors of/in the schools, in particular. their varied contexts. To this end, we advocate a path to otherness in curriculum policies, especially math, that replaces curriculum prescription as a paradigm and is guided by an inversion of the curriculum vector, which produces a movement capable of embracing cultural diversity and the difference, represented by the reception of disruptive situations, controversies. and daily problems that mark the school territory.
\end{abstract}

Keywords: Curriculum. Pragmatic Sociology. Differences.

\section{ALTERIDAD EN LOS PLANES DE ESTUDIO MATEMÁTICOS: LA INVERSIÓN DEL VECTOR Y LA ACCIÓN DE ACTORES EN LA ESCUELA}

Resumen: En este texto, nuestro propósito es describir la convergencia de la investigación sobre políticas curriculares que han enfatizado la necesidad de que la macropolítica tenga como principio estructurante un cierto grado de permeabilidad en relación con la acción y el tiempo de los actores locales en / en las escuelas, en particular. sus variados contextos. Con este fin, abogamos por un camino hacia la otredad en las políticas curriculares, especialmente matemáticas, que reemplaza la prescripción curricular como paradigma y se guía por una inversión del vector curricular que produce un movimiento capaz de abarcar la diversidad cultural y la diferencia, representada por la recepción de situaciones disruptivas, controversias. y problemas diarios que marcan el territorio escolar.

Palabras clave: Currículum. Sociología pragmática. Diferencias.

Submetido em Agosto de 2019

Aprovado em Dezembro de 2019

Revista Teias v. $20 \bullet$ n. 59 • out/dez 2019 • Outras epistemologias e metodologias nas investigações sobre currículo 121 